\title{
O ESPETÁCULO DE SI: UMA PROPOSIÇÃO SOBRE A ATUALIDADE DA SOCIEDADE DO ESPETÁCULO
}

\author{
THE OURSELVES SPECTACLE: A PROPOSAL ON THE \\ PRESENTATION OF THE SOCIETY OF THE SPECTACLE \\ EL ESPECTÁCULO DE SI: UNA PROPOSICIÓN SOBRE LA \\ ACTUALIDAD DE LA SOCIEDAD DEL ESPECTÁCULO
}

\author{
Marsiel Pacífico ${ }^{1}$ \\ LuIZ RoBERTO GOMES ${ }^{2}$ \\ Universidade Federal do Amazonas (UFAM), Manaus/AM - Brasil ${ }^{1}$ \\ Universidade Federal de São Carlos (UFSCar), São Carlos/SP - Brasil ${ }^{2}$
}

Resumo Na compreensão das novas formas de dominação do capitalismo, Guy Debord, na obra $A$ sociedade do espetáculo, apresenta um segundo momento do capital fundado sobre o espetáculo que, enquanto sofisticação do fetiche da mercadoria, se consolida como fundamento da vida social. Todavia, a dinâmica viva do sistema e a proliferação da imagem na sociedade contemporânea majoritariamente audiovisual dão novos contornos a esse conceito. O mundo hoje se encontra amplamente munido de aparatos que dominam a vida do sujeito em todas as instâncias, como os aparelhos televisores, celulares, iphones, ipads e ipods, além do computador; que os conecta ininterruptamente à grande rede que tudo e a todos comunica. A produção do espetáculo não mais se encerra na mercadoria, mas é um novo éthos comunicacional, intrínseco, que age como substituto da narrativa; é, em última instância, a forma existencial latente do mundo virtual, expressada por Türcke na máxima "quem não emite, não é". É neste cenário, no qual a imagetização da vida ganhou proporções inimagináveis, que acreditamos encontrar o cerne de um possível terceiro momento do capital: o espetáculo de si.

Palavras-chave: A sociedade do espetáculo; imagem; éthos comunicacional; espetáculo DE SI.

Abstract In the wake of understanding the new forms of capitalism domination, Guy Debord, in The Society of the Spectacle (1967), presents a second phase of capital based on 
the spectacle that while is a commodity fetish sophistication, also has consolidated itself as a foundation of social life. However, this concept has gained new shapes because of the proliferation of the image in our mostly audiovisual contemporary society. The world today is largely equipped with devices that dominate our lives in all instances and seamlessly connects us to the wide world web, such as television sets, cell phones, iPhones, iPads, iPods and computers. Now, the center of the spectacle production is not the merchandise, but a new communicational ethos, intrinsic, that works as a narrative substitute; it is, in the last instance, the latent existential form of the virtual world, masterfully expressed by Türcke in the expression "who does not emit, is not". We believe we founding this scenario, in which the image obsession has gained unimaginable proportions, the core of a possible third phase of the capital: the spectacle of ourselves.

KEYWORDS: THE SOCIETY OF THE SPETACLE; IMAGE; COMMUNICATIONAL ETHOS; SPETACLE OF OURSELVES.

RESUmen En la comprensión de las nuevas formas de dominación del capitalismo, Guy Debord, en la obra La Sociedad del Espectáculo (1967), presenta un segundo momento del capital fundado sobre el espectáculo que, como sofisticación del fetiche de la mercancía, se consolida como fundamento de la vida social. Sin embargo, la dinámica viva del sistema y la proliferación de la imagen en la sociedad contemporánea mayoritariamente audiovisual dan nuevos contornos a este concepto. El mundo hoy se encuentra ampliamente provisto de aparatos que dominan la vida del sujeto en todas las instancias, como los aparatos televisores, celulares, iphones, ipads y ipods, además de la computadora; Que los conecta ininterrumpidamente a la gran red que todo ya todos comunica. La producción del espectáculo ya no se cierra en la mercancía, pero es un nuevo éthos comunicacional, intrínseco, que actúa como sustituto de la narrativa; Es en última instancia la forma existencial latente del mundo virtual, expresada por Türcke en la máxima "quien no emite, no es". En este escenario, en el que la imagentización de la vida ganó proporciones inimaginables, que creemos encontrar el núcleo de un posible tercer momento del capital: el espectáculo de sí.

Palabras Clave: La sociedad del espectáculo; imagen; Éxos comunicaciones; espectácuLO DE Sí.

\section{INTRODUÇÃo}

Como componente fundamental do capitalismo moderno, o espetáculo encontra-se no âmbito da cultura digital, delineando-se como um novo éthos comunicacional, meio pelo qual transitam as ideias e as coisas, e se constituem subjetividades e sujeitos. Se, ao diagnosticar uma sociedade espetacularizada, Debord fazia menção ao seu tempo e espaço, quais seriam as atuais características do espetáculo de uma sociedade, em tempos da cultura digital, na qual a onipresença dos meios digitais e a força imperativa destes atuam sobre o nosso cotidiano? Dessa forma, pretendemos demonstrar, a partir da compreensão de que 
vivemos "a constituição de uma nova cultura, fortemente influenciada pelas tecnologias digitais, e que tem como característica essencial a estrutura de rede como fundamento desse novo modelo de organização social" (GOMES, 2015, p. 134), que os impactos da revolução tecnológica reorganizaram nossa subjetividade, a ponto de produzir uma forma nova e única de expressão, comum nos ambientes virtuais; forma que guarda as características do espetáculo, mas que anuncia um novo produto: nossa própria vida privada.

Em um mundo no qual cada vez menos nota-se a barreira outrora sólida que separava o real do virtual, a mediação tecnologizada da interação entre os sujeitos passa a agregar novos contornos às relações humanas: a instantaneidade ao alcance de um clique, a reconfiguração do tempo e do espaço, a multiplicidade das tarefas exercidas simultaneamente, a construção da identidade e das identidades alocadas nos avatares; enfim, são inúmeras as reconfigurações estabelecidas. Todavia, a plataforma que serve de alicerce para tantos desdobramentos parece ter, ela própria, transfigurado-se.

Adorno e Horkheimer, em sua célebre obra, Dialética do Esclarecimento: Fragmentos Filosóficos (1985), demonstram como no iluminismo o homem toma para si o projeto de utilizar o esclarecimento em prol da construção de uma realidade social emancipatória, mas, paradoxalmente, tal projeto não se concretiza e a estrutura de uma sociedade esclarecida autodestrói o conhecimento, visto que o pensar automatizou-se e reificou-se nos indivíduos, anulando a forma clássica da razão. Paulatinamente, o domínio da razão, centro do projeto Iluminista, ao libertar-se dos grilhões metafísicos, foi dando lugar ao desenvolvimento da racionalidade instrumental. Neste contexto, "a naturalização dos homens hoje não é dissociável do progresso social" (ADORNO; HORKHEIMER, 1985, p.14) e o evoluir das condições econômicas da sociedade tem como alicerce a regressão de seu substrato mais fino: o esclarecimento. Esse esclarecimento, que parecemos ter alcançado, nada mais é do que a elevação irracional do pensamento lógico matemático a todas as esferas da vida humana; neste meio, o que há de mais rico e verdadeiramente transcendente na potência do pensar, ou seja, a subjetividade é decomposta pelo modelo em que "o que não se submete ao critério da calculabilidade e da utilidade torna-se suspeito para o esclarecimento" (ADORNO; HORKHEIMER, 1985, p.19).

Tal dialética do esclarecimento derrama suas formas sobre incontáveis aspectos da vida social e suas mediações, determinando de maneira irrestrita a produção dos bens simbólicos no campo da linguagem e da cultura. As expressões humanas afeitas à esfera da subjetividade esvaziaram-se de seu sentido emancipatório para reproduzirem valores que convergem à razão instrumental e ao mercado. Se as músicas e os filmes, por exemplo, têm no avançar do aparato técnico a ampliação única de suas formas de composição, por outro lado, apresentam na prática um alinhamento, de forma e conteúdo, típico de produtos que são concebidos para serem vendidos em larga escala. Da mesma maneira, as possibilidades de expressão no âmbito digital são, teoricamente, quase infinitas; todavia, os reiterados modos de repetição na estrutura e na forma da comunicação são decisivos para que derive a mesma análise. O alto custo do progresso é a instauração de um processo social amplo e onipresente de semiformação, conforme expresso na máxima de Adorno e Horkheimer: "a 
terra totalmente esclarecida resplandece sob o signo de uma calamidade triunfal" (ADORNO; HORKHEIMER, 1985, p. 17).

Ocorre que, contemporaneamente, em tempos de ciberespaço, de cultura digital e do massivo acesso aos aparelhos de tecnologia audiovisual, sobretudo a televisão e o computador, as células de força da Indústria Cultural encontram sua máxima potência na sofisticação imagética do espetáculo. No desenvolvimento das estruturas do capital está a superação das formas tradicionais coercitivas de poder, para o avançar de um modo estético sutil de sedução, que direciona suas capacidades técnicas para que, através das sensações, possam imputar os desejos e vontades ditadas pela maquinaria da Indústria Cultural.

Assim, a estetização do capital pelo caráter do espetáculo se estabelece como mediação entre o homem e as coisas e, em última instância, determina a relação dos homens com seus pares.

Ao mesmo tempo, o mundo que orbita em torno da imagem que produz de si mesmo passa, em certa medida, pelo distanciamento da limitação que a objetividade impõe. No momento em que "a realidade surge no espetáculo, e o espetáculo é real" (DEBORD, 1997, p. 15), a própria realidade passa a habitar e reificar o locus da alienação. A sociedade produzida e produtora do espetáculo impele a lógica da exteriorização; aquilo que não está fixado à flor da pele, que não se deixa transparecer, sucumbe à lógica do "o que aparece é bom, o que é bom aparece” (DEBORD, 1997, p. 16-17). Não está posta somente a elevação do falso, mas, sobretudo, a determinação de que "no mundo realmente invertido, a verdade é um momento do falso" (DEBORD, 1997, p. 16). Desta feita, o segundo momento do capital descrito por Debord (1997) impõe uma dura lógica aos conceitos e experiências: ou o esquecimento ou a falsificação.

$\mathrm{Na}$ atualização da leitura do momento da imagem no capital, Christoph Türcke observa o mesmo processo no tocante às notícias; aquilo a quem denomina de "fronteira da falsificação" (TÜRCKE, 2010, p. 16) nada mais é do que a tradução da lógica do espetáculo para a formatação da imprensa. Qualquer enquadramento de um todo ao instante do espetáculo perde a sua carga de conteúdos que estão subcutaneamente entranhados pela essência que a imagem não consegue (e não se dispõe) a capturar. O tempo do espetáculo é o instante e dele se apartam, perdidos no universo de significações, a polissemia de sentidos que o velho ato narrativo carregava: "o espetáculo, como organização social da paralisia da história e da memória, do abandono da história que se erige sobre a base do tempo histórico, é a falsa consciência do tempo" (DEBORD, 1997, p. 108). Se o ato comunicativo trazia em seu âmago a função de comunicar, de transmitir a sabedoria, na configuração que o espetáculo lhe outorga, não há finalidade que não seja o próprio meio.

A constatação de que "o definhar da narração tem seu gérmen no crescimento exponencial da força da linguagem visual da Indústria Cultural” (PACÍFICO, 2012, p. 24) não decorre pura e simples de sua estetização; mas passa fundamentalmente pela perda de qualquer função da linguagem que não seja a própria linguagem do sistema, ou seja, o espetáculo:

O caráter fundamentalmente tautológico do espetáculo decorre do simples fato de seus meios serem, ao mesmo tempo, seu fim. É o sol que nunca se põe no 
império da passividade moderna. Recobre toda a superfície do mundo e está indefinidamente impregnado de sua própria glória. A sociedade que se baseia na indústria moderna não é fortuita e superficialmente espetacular, ela é fundamentalmente espetaculoísta. No espetáculo, imagem da economia reinante, o fim não é nada, o desenrolar é tudo. O espetáculo não deseja chegar a nada que não seja ele mesmo (DEBORD, 1997, p. 17).

Se no caráter do mundo invertido do espetáculo toda força linguística se concentra em produzir a própria imagem, os medos se interiorizam nas entranhas de nosso corpo social e, embora aparentemente escondidos, são as indissoluções que nos impelem à adesão ao “comportamento hipnótico (...) tendência a fazer ver" (DEBORD, 1997, p. 18).

Os processos técnicos modernos não somente concentraram o contexto de nossas interações em um ambiente virtual, mas também a reconfiguraram a partir de diretrizes específicas do ambiente citado. Ao direcionar as suas forças comunicativas para o objetivo de se destacar em meio ao turbilhão de imagens que fervilham nas redes sociais, alcançamos uma modalidade nova no estágio social do espetáculo: a sociedade não é somente $d a$ imagem, mas, sobretudo, para a imagem. Podemos observar este mecanismo em diversos espaços virtuais contemporâneos.

Se fizermos uma rápida visita às páginas virtuais de relacionamentos pessoais, certamente iremos observar como os sujeitos, cada vez mais, compactuam da necessidade de expor sua vida, seus feitos e suas intimidades, num fórum acessível a todos. É por esse contexto que as fotos têm sua estética e função reconfiguradas; se antes a imagem servia como recordação de uma memória estabelecida pela relação de experiência entre sujeitos ou entre sujeito e objeto e, portanto, retratava o interlocutor do ato como forma de resgatar tais lembranças, a função da fotografia pessoal passa a ser, paradoxalmente, condicionada ao terceiro elemento - o observador virtual.

A onda das selfies ${ }^{l}$ expressa a necessidade do sujeito em comprovar e expor aos integrantes de seus círculos de relacionamento pessoal e virtual que ele esteve presente naquele evento. Documentar uma viagem, uma conquista ou um ato corriqueiro é mais do que parte integrante do mesmo; torna-se elemento essencial sem o qual o fato em si não faria sentido; de tal modo, que o prazer do ato não pertence mais à sua realização, mas desloca-se gradativamente para a sua imagetização espetacular.

Se as promessas das imagens do capital se tornam vãs e o exercício de reconhecer o distanciamento entre a vida objetiva e o mundo ideal criado pelas propagandas é doloroso, o apaziguamento dessas tensões opostas se dará na reificação imagética da ilusão.

\footnotetext{
1 O termo selfie foi popularizado nos últimos anos, como forma de autoexposição imagética predominantemente nas redes sociais. A palavra deriva do termo self mais o sufixo ie, e designa o hábito amplamente difundido das pessoas em se autorretratarem por meio de fotografias, e postarem as mesmas nas redes sociais. Tal prática ocorre como mediadora de experiências em múltiplos cenários, e são habituais e cenas cotidianas, em eventos, viagens ou em encontros com pessoas famosas, entre outras. O tamanho da sua popularização fez que o dicionário Oxford incluísse seu verbete no ano de 2013, mesmo ano em que mensalmente foram aferidos a ocorrência do termo em 150 milhões de vezes por mês.
} 
O exemplo do caso de Catarina Migliorini, que ficou famosa por leiloar pela internet sua virgindade nos faz, por vezes, acreditarmos que tais fatos ocorrem isoladamente e, de tão raros, ganham repercussão. Porém, quando zapeamos os canais da twitcam,${ }^{2}$ constatamos, sem esforços, os inúmeros usuários que oferecem o espetáculo do próprio corpo em troca da atenção dos internautas, em um leilão de ego e de audiência, no qual o aparecer se efetiva brutalmente enquanto ser, existir.

A lógica que se estabelece por quanto mais views ${ }^{3}$ em meu canal, menos roupa em meu corpo é a cristalização do prazer da exposição como ápice da realização do ato. Um eventual interesse financeiro ou, sobretudo, a possibilidade da satisfação da pulsão sexual secundarizam-se frente ao espetáculo narcísico da exposição pública do corpo.

Como modelo desse movimento, podemos citar também o icônico caso de Tess Chris$\operatorname{tian}^{4}$ que, para além das suas possibilidades de comprovação, sintetiza o espírito de uma época, no qual o primado estético ganha tamanha soberania sobre sua dimensão objetiva que, para alimentar a imagem da melhor maneira possível, vale-se de qualquer sacrifício. A opção por não viver o aqui em decorrência do que será representado de si ali está muito além da estética dos "dentes deslumbrantemente brancos" (ADORNO; HORKHEIMER, 1985, p. 138) discutida por Adorno e Horkheimer. Nesse contexto, a projeção da imagem pessoal abandona seu caráter de exercício estético, cujo posto era um aprazível engodo, para se situar como função primária da vida objetiva.

Ao nos debruçarmos sobre os obscuros sites da Deepweb, ${ }^{5}$ podemos encontrar, cada vez mais com uma frequência mais regular, pessoas que oferecem seu ato derradeiro, um atentado contra a própria vida, para que todos aqueles que acessarem seu canal tenham o gozo de sua morte. O suicídio assistido ao vivo por milhares de usuários do mundo todo configura-se como ato final do espetáculo narcísico da vida. Também nos parece razoável a analogia na qual a atualização constante da própria vida nos sítios virtuais é a superextensão do ato comunicacional da notícia.

Em todos esses exemplos emerge um novo contexto que merece ser observado; se esses não são casos isolados mas, ao contrário, parecem a tônica de nosso tempo, no qual

2 Twitcam é a extensão audiovisual do microblog Twitter. Nela, cada usuário disponibiliza a imagem de sua webcam como um canal ao vivo. Outra característica fundamental é o contador de visualizações, que demonstra em tempo real quantas pessoas estão conectadas àquele canal.

3 Views são marcadores comuns em plataformas virtuais que permitem ao servidor do canal acompanhar quantas pessoas estão assistindo o conteúdo que ele emite.

4 Segundo o portal Daily Mail, que noticiou a história em $1^{\circ}$ de fevereiro de 2015, Tess Christian tomou a decisão de nunca mais sorrir aos 10 anos de idade. Seu objetivo era que, a partir do não exercício de seus músculos faciais, fossem evitadas rugas e marcas de expressão. Quarenta anos depois, corroborada por diversas fotos e relatos de pessoas próximas, a própria Tess sintetiza sua experiência da seguinte maneira: "Não tenho rugas porque controlo os meus músculos faciais. Toda gente me pergunta se pus Botox, mas não pus. Sei que é porque não rio desde que era adolescente. A minha dedicação compensou - não tenho uma única ruga na cara".

5 A Deepweb refere-se ao conteúdo da internet que não pode ser acessado pelos mecanismos de buscas comuns, nem pelos navegadores usuais. Dado a falta de controle, seu espaço é propício para uma diversificada gama de conteúdos, desde páginas pessoais a fóruns recheados de imagens. Seu site mais conhecido é o 4chan. Neste site, um dos tópicos mais movimentados é o que se refere ao suicídio. 
as imagens se absolutizam em todas as esferas da vida social e na produção da cultura, faz-se necessário investigar as matrizes sociais que têm produzido uma nova modalidade comunicativa também mediada pelas imagens, um éthos linguístico cujo expressar/comunicar dá lugar ao expor/ser visto de forma espetacular em um sentido novo e específico: $o$ espetáculo de si.

\section{NOVAS FORMAS do ESPETÁCULO: O ESPETÁCULO DE SI}

As matrizes dos processos de imagetização da vida e da cultura, que hoje encontram seus ápices, já demonstravam suas raízes no pensamento de Guy Debord. A constatação do autor exposta nas primeiras linhas de sua obra Sociedade do Espetáculo soava como um alarde: "Toda a vida das sociedades nas quais reinam as modernas condições de produção se apresenta como uma imensa acumulação de espetáculos” (DEBORD, 1997, p. 13). A definição de Debord anuncia um momento moderno do capital, no qual o protagonismo da imagem se evidenciava. No âmbito comunicacional, a consolidação dos meios massivos, como o cinema e a televisão, cujo caráter imagético é preponderante, centralizava uma mudança de paradigma que também poderia ser percebido na análise dos jornais e das propagandas: a imagem reinante do espetáculo se instaurava pelos caminhos da linguagem. O que está posto nesta mudança histórica não é somente a mudança do meio da mensagem, mas de toda a sua forma, conteúdo e propósito.

Diante deste contexto, parece relevante que ao diagnóstico do capital cabia uma atualização fundamental: o processo histórico havia atravessado pelos seus múltiplos processos que reverberavam pela mediação da imagem, transferido o protagonismo do sistema à sua própria sombra.

Convergentemente, anos antes, Adorno e Horkheimer publicavam a Dialética do Esclarecimento, obra que trouxe ao glossário filosófico o conceito de Indústria Cultural. Indústria Cultural, ou Kulturindustrie em alemão, é um termo na célebre obra Dialética do Esclarecimento (1944), cuja expressão faz menção à forma como a cultura está inserida na sociedade capitalista, que a converte em mercadoria, de modo a redirecionar seu norte para o consumismo. Assim, o termo denota a necessidade que o sistema social vigente tem, como modo de autopreservação, em formatar as subjetividades dos indivíduos de modo a padronizar e direcionar os impulsos para atender à sua lógica mercantil, estimulando o consumo de forma ininterrupta. Para tal, a Indústria Cultural lança mão de todo artefato tecnológico, principalmente os meios de comunicação que hoje são amplamente difundidos, para estimular a vontade das massas. Tal conceito desvelava o papel nuclear da massificação e industrialização da cultura como forma subjetiva de reificação do capital. Nesse contexto, o espírito da semiformação se propaga na medida em que:

Os indivíduos inseridos no seio da Indústria Cultural são seduzidos por estímulos mercantis, sobretudo os de natureza estética, que são propositalmente codificados segundo as necessidades do mercado e sua lógica consumista, para 
estimular nos sujeitos desejos massificados falsamente associados a promessas ilusórias de aquisição de sentimentos, que a mesma estrutura de dominação lhes usurpa, como felicidade e satisfação, sem ainda mencionar, a maneira como a Indústria Cultural torna o indivíduo nulo na subsunção de sua subjetividade em favor do capital, e paradoxalmente, lhe promete sanar por meio da adesão a uma agenda de consumo, seus desejos utópicos, como o desejo da onipotência. Nesse processo dialético e dicotômico, onde o indivíduo está entre deuses e o nada, o capitalismo se perpetua e se reafirma (DONATO; PACÍFICO, 2011, p. 537).

Desse modo, a proposição teórica dos autores evidencia como, no esteio da estetização do capital, está inerente a imposição assídua de um modo subjetivo determinado por essas mediações. O caráter incessante desses estímulos está nas suas diversificadas formas de expressão, que sempre convergem para o mesmo ponto da sensatio do sujeito: o consumo.

Não por acaso, as obras de Debord, Adorno e Horkheimer afluem mais uma vez ao expor a constituição do tempo vivido fora da produção ou tempo livre. Na medida em que o objetivo simbólico do sistema é a produção de um padrão de consumo predeterminado e mediado pelas seduções estéticas, a formação do prazer em torno do consumo da mercadoria necessita da adoção do caráter de lazer e do status da liberdade. A função do espetáculo seria completamente desfeita se, em contato unívoco e deliberado com a mercadoria, sem seus jogos simbólicos e seus estímulos visuais, sem a sedução e os choques imagéticos, não pudéssemos conceber a natureza do papel da mercadoria nas engrenagens do capital. A relação entre o sujeito e o produto está muito mais intrincada sob seus aspectos simbólicos do que sua dimensão objetiva. Não caberia à propaganda um discurso sincero e pragmático, com a precisão científica do positivismo mais elevado. Ela precisa, através de sua linguagem, alcançar a todas as formas de orientação da vida e dos desejos dos sujeitos.

Tal dimensão parece alcançar igualmente as formas de expressão dos homens. Nas fotos, vídeos e outras formas de representação nas redes sociais estão em jogo mais do que um ato simples de exposição individual, mas, sobretudo, um apelo estético que visa canalizar os olhares dispersos para aquele espetáculo individual. O jogo de sedução da propaganda empresta seu caráter aos sujeitos que seguem a mesma lógica do espetáculo mercantil, no qual não basta somente a exposição fria, mas o protagonismo está sobre os mecanismos de sedução.

A lógica do mercado que se instaura sobre as imagens é concomitante à ampliação de sua dimensão sensacionalista. Assim, para toda mediação imagética, essa fórmula combinatória impõe uma lógica concorrencial que vetoriza as forças da constituição simbólica da linguagem como formas de espetáculo concentrados. Se as propagandas já concorriam entre si e prevaleciam à medida que se adequavam à égide da sensação, tal modelo se alastra desde os objetos exteriores mediados pela imagem até o nosso modo íntimo de compreender e se expressar. Como explica Christoph Türcke, ao referir-se ao contexto das notícias: 
O que atinge, toca, comove é aquilo que, enquanto injeção, foi agudizando o suficiente o nosso sistema nervoso e, ainda que seja apenas por um instante, chama a atenção. (...) Ou seja, se tudo o que não está em condições de causar uma sensação tende a desaparecer sob o fluxo de informações, praticamente não sendo mais percebido, então isso quer dizer, inversamente, que o rumo vai na direção de que apenas o que causa sensação é percebido (TÜRCKE, 2010, p. 20).

O espetáculo que habita as imagens parece um sedativo moderno extremamente sofisticado, que nos circunda e transpassa, levando consigo a capacidade de espantar-se. A experiência perde suas potencialidades formativas ao inebriar-se do suntuoso espetáculo de cores, imagens e sensações, cuja síntese estabelecida entre forma e conteúdo inibe o desenvolvimento do pensamento autônomo e a sua conseguinte dimensão emancipatória. A banalidade das distorções e antagonismos do nosso projeto moderno de sociedade passa fundamentalmente pelas sensações produzidas pelos sucessivos e ininterruptos fragmentos imagéticos que, acelerados, levam-nos à letargia; a contemplação do espetáculo das imagens na Indústria Cultural é, ao mesmo tempo, a fuga do olhar sobre a concretude do mundo.

O patamar espetacular alcançado pela imagem é uma potencialização da dinâmica do capital, que ressignifica a seu modo não somente sua lógica interna, mas também e fundamentalmente a relação do homem com o mundo e sua relação consigo mesmo e com seus pares. Se as imagens estão no interior da tecnificação das relações sociais, entender a força exercida pela imagem, nesse contexto, demanda o mapeamento das novas significações denotadas pelo espetáculo de si.

Assim, o espetáculo define os trilhos para se emancipar da propaganda e replicar-se nos atos comunicativos dos homens. Os jogos simbólicos da propaganda expandem seus horizontes para além da dimensão do trabalho e do consumo: ao firmar-se pelo seu contrário, o tempo livre alinha-se com a estrutura do trabalho e a demanda de sua produção difundidas pela dimensão sedutora de suas imagens. $\mathrm{O}$ caráter incessante do sistema não produz somente a linguagem da coisa sobre o sujeito, mas também a própria linguagem do sujeito.

Todavia, não estão ignoradas, nesse contexto, as dimensões objetivas do capital: a relação infraestrutura e superestrutura proposta por Marx parecia, no mínimo, digna de revisão. Tal revisão foi proposta por Debord, prenunciando uma segunda etapa do capital. Em um primeiro momento, o estímulo ao lucro e à acumulação de capital condensados pelo espírito do capitalismo possibilitou, gradativamente, o estreitamento da relação entre ser e ter, até alcançar o ponto de sua total inversão. Assim sendo, o reconhecimento simbólico social desassociou-se do espírito religioso que fomentava valores de uma conduta ética ascética, para condicionar-se ao dinheiro. O contexto histórico da Sociedade do Espetáculo permitiu ao autor constatar um novo patamar desse processo:

A primeira fase da dominação da economia sobre a vida social acarretou no modo de definir toda realização humana, uma evidente degradação do ser para o ter. A fase atual, em que a vida social está totalmente tomada pelos resultados acumulados da economia, leva a um deslizamento generalizado do ter para o 
parecer, do qual todo "ter" efetivo deve extrair seu prestígio imediato e sua função última (DEBORD, 1997, p. 18).

Nessa nova fase do capital, para além das formas de produção e da cisão entre as classes sociais, estão presentes os elementos decisivos para a compreensão do irracionalismo da subjetivação do desejo consumista. Tal espírito não se encontra objetivado nessa notícia ou naquela propaganda, mas, de um modo inverso, dá-se essencialmente a relação entre as imagens na relação entre si e com os sujeitos: "o espetáculo não é um conjunto de imagens, mas uma relação social entre pessoas, mediada por imagens" (DEBORD, 1997, p. 14).

O espetáculo, tal qual se apresenta no capitalismo moderno, anuncia a mercadoria na mesma medida que transforma o sujeito. Tece-lhe sentidos, desejos e modos, afasta-o de uma visão plural e impele-o a, cada vez mais, olhar somente para si. Para Guy Debord, as imagens no capitalismo haviam se convertido em uma realidade projetada que, embora fossem apenas sombras do real, espetacularizavam-se enquanto essência primária da realidade.

As imagens se articulariam de tal modo que, gradativamente, abarcavam na lógica do fetiche da mercadoria e, portanto, na vida dos sujeitos em sua totalidade. Tal ideia é elucidada pelo autor por distinguir que "o espetáculo não é um conjunto de imagens, mas uma relação social entre pessoas, mediatizadas por imagens" (DEBORD, 1997, p. 14). Tal impressão é corroborada por Türcke, quando o filósofo expõe sua argumentação sobre a sensação absoluta, visto que, segundo o autor: "O essencial nas coisas não é o interior invisível, e sim o aspecto exterior” (TÜRCKE, 2010, p. 179).

Enquanto sofisticação do fetiche da mercadoria, a imagem atuaria no mundo moderno, segundo Guy Debord, com sentido de aproximação entre o espírito da mercadoria e o espírito do sujeito, em uma adequação que se inclina para um alinhamento espetaculoso; uma inversão iconoclasta já anunciada na ideia de fetiche da mercadoria, na medida em que homem e coisa passam a ser representados enquanto coisa e homem. E essa disciplinarização tem seu espírito categórico exposto com distinção por Türcke, ao analisar o fenômeno Big Brother e a massiva adesão voluntária dos inscritos para participarem do reality show:

\footnotetext{
Entenda-se bem, de livre e espontânea vontade; uma vontade tão livre e espontânea quanto a das mariposas voando em torno da lâmpada. Ninguém as coage. De um ponto de vista puramente técnico, poderiam muito bem desviar sua rota de voo. A decisão é de cada um (TÜRCKE, 2010, p. 57).
}

Desse modo, as relações entre as imagens tornaram-se, enquanto estrutura das relações sociais dos sujeitos, relações sociais integradoras e desintegradoras, que separam o sujeito da realidade, mas o aglutinam a outros sujeitos em uma massa distraída pelas luzes e efeitos do espetáculo social. A administração do tempo e do espaço, das relações do homem para com o homem e do homem para com o mundo são mediadas pela sucessão de imagens interpostas entre o ser e o saber, ou seja, é aquilo que constitui a verdade instantânea e superficial, mas, ao mesmo tempo, dificulta severamente as possibilidades do olhar profundo que desvelaria a verdade acobertada. 
A profundidade, aliás, não é um aliado do espetáculo social; sua essência é o da inversão, da falácia e do fim em si mesmo; como explicita o próprio autor quando afirma que:

\begin{abstract}
O caráter fundamentalmente tautológico do espetáculo decorre do simples fato dos seus meios serem ao mesmo tempo a sua finalidade (...) No espetáculo da imagem da economia reinante, o fim não é nada, o desenvolvimento é tudo. O espetáculo não quer chegar a outra coisa senão a si mesmo (DEBORD, 1997, p. 17).
\end{abstract}

O conjunto de formas e características do espetáculo na sociedade contemporânea tange, concomitantemente, novas modalidades e sentidos na linguagem. Nesse sentido, faz jus à observação de Türcke quanto à dinâmica comunicacional da notícia e da propaganda.

Desse modo, podemos compreender como a constituição de uma nova forma de linguagem é naturalmente desenvolvida com o avanço da força da imagem. A mediação linguística entre os sujeitos encerra em si o arcabouço de novas formas de configuração social e ao mesmo tempo pessoal. O conceito de sociedade do espetáculo deriva do espetáculo social que, por sua vez, demanda uma mediação simbólica igualmente espetacular: um autoespetáculo, o espetáculo de si; no qual a linguagem tenta, a todo custo, salvar algo de pessoal e individual em meio à tormenta imagética de pixels e estímulos que seduzem e impelem ao consumo e às mercadorias.

Todavia, há no atual contexto social o processo de potencialização do comportamento hipnótico para uma modalidade individual, cujo objeto de imagetização é o próprio sujeito. Ao promover-se enquanto produto espetacular, desenvolve-se um processo ambiguamente pessoal; a singularidade que aposta na autoexposição do sujeito a um espetáculo de si acaba, no passo seguinte, fracassando pois, ao mesmo tempo em que deseja insaciavelmente demarcar algum rastro de singularidade, perde-se na multidão de seus pares, que repetem o mesmo gesto no velho simulacro das propagandas dos produtos da Indústria Cultural: com o verniz da exclusividade, intensifica o processo de massificação subjetiva, que convém ao acelerado ritmo que a tecnologia conferiu ao modo de produção. A fixação sintetizada em uma selfie não pode reter a liquidez da quantidade e da variedade da selfies expostas nas redes sociais a cada segundo.

E assim, de modo mais ou menos contundente, o monopólio do espetáculo impõe-se sobre as esferas da produção da vida humana, encontrando-se no atual estágio no qual "as sensações estão a ponto de se tornar as marcas de orientação e as batidas do pulso da vida social como um todo" (TÜRCKE, 2010, p. 14). Nas propagandas, nas notícias, nos meios de comunicação, na industrialização das artes e, por fim, em nós mesmos; sob o signo inocente e despretensioso do entretenimento, as imagens escondem as células da reificação do modo vigente. A não concretização histórica do iluminismo e o descolamento das esperanças metafísicas da religião nos abandonaram nus e ainda mais frágeis. Como reflexos de nossa pequenez, o homem projeta nas imagens a mentira de si e do mundo, utopia que aguça os sentidos, seduz os corpos, mas não alimenta as almas. Desse modo, ao fundo da tessitura social imagética encontram-se projetados nossos medos que, na amálgama de 
aflições primitivas e angústias tecnificadas, revestem nossa modernidade de uma aparência altamente tecnológica e de uma essência proporcionalmente enfraquecida.

Na medida em que opera sobre os sujeitos, a semiformação impele no espírito a reafirmação e reprodução incessante dos valores e verdades constituídos pela Indústria Cultural. O conceito de semiformação ou semicultura (Halbbildung) em Adorno é a compreensão de que os meios para a consolidação da formação (Bildung), almejados pelo espírito moderno, não se efetivaram derivando uma crise profunda da cultura. No desenvolvimento do capitalismo tardio, a cultura converteu-se em mercadoria, esvaziando as possibilidades de reflexão crítica de um espírito que, objetificado, coisificou-se. Neste sentido, as expressões virtuais da exposição espetaculosa da vida privada são dimensões semiformativas na medida que condensam, virtualmente, a subjetividade dos indivíduos a partir de um padrão comunicacional, cujas raízes remetem às propagandas e a mercadoria. Somos, no ciberespaço, expressões "propagandeosas" da nossa vida, na busca da resolução da angústia da não existência que, agora, está mediada pela audiência. Assim, a (des)educação não age ingenuamente para um lado arbitrário qualquer, mas, de igual modo, manipula astuciosamente os sentidos para que estes se viciem e se comuniquem da forma espetacularizada. Sendo assim, nos parece plausível pensar ou questionar o conceito de espetáculo em Guy Debord como fundamento de um novo éthos linguístico. Buscamos compreender e demonstrar como tal conceito se transfigura para uma nova fase, que denominaremos espetáculo de si, pois, por si só, como exposto por Debord, o conceito de espetáculo não se caracteriza no sentido proposto.

O pensamento de Guy Debord, sobretudo o cerne de suas ideias encontrado em sua mais influente obra, A sociedade do espetáculo (1967), foi, em sua época, um polarizador de conceitos contestatórios e críticos frente ao antagonismo social imposto pelo capitalismo. Nesse sentido, Debord e a Internacional Situacionista, grupo de ativismo político e artístico-cultural que tinha no autor um de seus pensadores mais ativos e influentes, foram vozes a reverberar profundamente no espírito do movimento civil o qual ficou conhecido como maio de 1968 francês. Todavia, sua potência crítica fundamenta-se sobre um momento específico do capital, a quem o próprio autor denominou cronologicamente de segundo, ou seja, o momento da imagem, ou como fora expresso em suas palavras, é "a evidente degradação do ser em ter" (DEBORD, 1997, p. 18), que naquele momento fluía para um estado de "busca generalizada do ter e do parecer" (DEBORD, 1997, p. 18). O novo contexto protagonizado pelos componentes virtuais e o próprio desenvolvimento do capital suscitam uma atualização da leitura do espetáculo e sua influência social, cultural, moral e estética:

A lixiviação desse sensório por meio do rufar de tambor audiovisual muda consideravelmente o significado da exploração. E se esse rufar do tambor finalmente começa a revolucionar as potências das conexões neurais elementares, as quais formam a base elementar de toda cultura, então a palavra "revolução" adquire uma nuança que nunca fora prevista no vocabulário socialista. Tudo isso está incluso no preço do espetáculo e demanda tanto uma iluminação neurofisiológica, psicanalítica e teológica quanto filosófico-histórica e teorético-social (TÜRCKE, 2010, p. 12). 
A partir de tal entrecruzamento, buscamos contribuir para a atualidade do pensamento sobre a educação, na medida em que demonstramos residir, no espetáculo de si, um modelo formativo e comunicacional que necessita ser investigado e submetido à crítica. Dessa forma, reunimos elementos suficientes para que possamos demonstrar um estado novo do espetáculo como forma substituta da narrativa na medida em que se configura como patamar soberano da linguagem. Nesse sentido, carregado do velho, mas com características e peculiaridades que o diferenciam, o espetáculo requer um reolhar, que anunciamos conceitualmente como o espetáculo de si.

Se Debord anunciava a passagem do ter em parecer, compreendemos que o parecer fora retirado das coisas e incorporado como característica fundamental do comportamento linguístico dos sujeitos, no qual a própria vida, projetada nas plataformas virtuais, compete em um jogo mercadológico de atenção, pautando-se na incessante venda da própria vida como espetáculo. Assim, no contexto hodierno, as pessoas não demonstram mais somente as coisas que têm, mas publicizam a própria vida.

A escolha dos termos na composição do conceito espetáculo de si suprime intencionalmente a palavra eu, pois compõe na sua forma o conteúdo de um conceito que denuncia um processo cultural amplo e coercitivo, que impõe um comportamento padronizado, na contramão da potencialidade da linguagem como forma expressiva singular, medium de resistência e possibilidade formativa.

\section{CONSIDERAÇÕES FINAIS}

A teoria como arcabouço, que visa compreender e explicar os fenômenos que habitam o mundo material, deve se atentar ao instante para esmiuçar o objeto enquanto categoria e também, projetar na imagem capturada do instante o prognóstico do futuro. Atentar-se ao futuro requer a reeducação do olhar, ou seja, o reolhar, a visita constante da teoria à prática, como ação que norteia e corrige a rota do pensamento.

Admitimos que o diagnóstico apresentado requer aprofundamentos e, para além disso, apresenta-se no escopo de outros conceitos, análises e autores que têm buscado refinar a compreensão sobre o imperativo da imagem e as determinantes de sua natureza no contexto da cibercultura. A compreensão, por exemplo, de que há uma “[...]nova relação entre imagem e linguagem" (QUÉAU, 2001, p. 91) exposta no conceito de imagem-síntese por Quéau, já há tempos apontava criticamente, a partir de suas premissas e categorias analíticas, para o mesmo fato: a interiorização linguística e comportamental de um modo específico se desenvolvia a partir do avanço tecnológico digital. Desse modo, o presente artigo busca articular tal temática a uma característica específica: o recondicionamento da linguagem a partir de uma dimensão espetacular, pois nos parece plausível afirmar que o conceito de espetáculo cunhado por Debord vive hoje sobre outras bases; outro instante da vida social, que traz novos sentidos e significados para a sua efetividade e para o seu papel no espírito formativo de nosso tempo. Fundamentalmente, a transição da linguagem das mercadorias, expressa na propaganda, atravessou a fronteira do objeto e se detém sobre nossas formas 
de comunicação e expressão nos ambientes virtuais. Diante do novo marco ontológico, buscamos, intensamente, a atenção, o olhar do outro e a singularidade do destaque que, em termos práticos, nos igualam e nos reúnem sob o alicerce da mesma mediocridade, na disputa incessante do consumo virtual da nossa vida como espetáculo: o espetáculo de si.

Mas se o espetáculo de si é um processo amplamente difundido, protagonista das formas de comunicação e expressão contemporâneas, de que modo se poderia constituir uma força de resistência a seu comportamento hipnótico? Dada a amplitude do processo de dominação simbólica, os ensaios de resistência se tornam fragilizados e escassos. Em cenários como este, é sempre prudente apegar-se a princípios fundamentais. De tal modo, primeiramente caberia à educação a destituição da barbárie como momento do espetáculo. O poder da produção de excitação em episódios extremos, como os casos de violência e morte, foram percebidos e utilizados muito antes do advento da era digital. $\mathrm{Na}$ imprensa, esse fenômeno se consolidou há tempos, como o icônico exemplo do Bild, jornal alemão (TÜRCKE, 2010, p. 13). Esse formato que virou modelo jornalístico e cresceu exponencialmente com o desenvolvimento dos aparatos técnicos que permitiram dar ênfase gráfica aos eventos, se torna, dentro do contexto do espetáculo de si, forma de autoviolência em troca de audiência. Além disso, em nossa sociedade, o contato com a brutalidade está posto desde muito cedo, sendo componente cada vez mais comum dos principais produtos audiovisuais voltados ao público infanto-juvenil, como os desenhos e os games. Essa exposição prolongada e irrestrita a episódios extremos formatados como espetáculo, cercados de prazer, estímulos e sensações, produz um gradativo distanciamento sensível, no qual a excitação cria um inerente amainamento do pensamento crítico e, por fim, enfraquece as possibilidades de resistência da própria dominação do éthos linguístico do espetáculo. Acostumar-se à barbárie, e portanto tornar-se insensível, é um processo consequentemente natural de uma sociedade espetacularizada. É preciso encarar esse problema criando espaços no qual a sala de aula se torne um lugar de reflexão sobre a barbárie, podendo se valer de formas expressivas e difundidas do espetáculo como pontos de partida para o aprofundamento da reflexão e do pensamento crítico. Assim, seria possível iniciar um processo de refluxo, no qual a razão incidisse sobre a sensação, invertendo seu jogo de primazia. Esse exercício, se contínuo, propiciaria um estado formativo no qual o desvelamento dos objetos específicos resultaria em uma prática generalizada da desconstrução dos processos de embrutecimento, substituindo a excitação frente à barbárie por um pensamento crítico dotado da sensibilidade humanizadora, que jamais deverá sair do horizonte da formação.

Assim, ainda que debilitadamente e imersas do caráter espetacular, estariam postas formas de resistência como garantias de uma margem de atuação autêntica sobre o mundo alienado: se o espetáculo de si é o éthos linguístico de nosso tempo, que possamos ao menos sermos os narradores de nosso próprio espetáculo e, talvez, com alguma sorte, façamos da vida uma obra de arte. 


\section{REFERÊNCIAS}

ADORNO, T. W.; HORKHEIMER, M. Dialética do esclarecimento: fragmentos filosóficos. Trad. Guido Antonio de Almeida. Rio de Janeiro: Jorge Zahar, 1985.

DEBORD, G. A sociedade do espetáculo. Tradução Estela dos Santos Abreu. Rio de Janeiro: Contraponto, 1997.

DONATO, H. Z.; PACÍFICO, M. Notas introdutórias sobre educação e emancipação em Theodor W. Adorno. In: Atos de pesquisa em educação, PPGE/ME FURB, v. 6, n. 2, p. 535-545, mai./ago. 2011. ISSN 1809-0354.

GOMES, L. (2015). Cultura Digital, Esfera Pública e Educação. Ixtli. Revista Latinoamericana de Filosofía de la Educación. 2(3). 129-145.

MARX, K. O capital. Lisboa: Editorial Progresso, 1996. v. I, livro primeiro.

PACÍFICO, M. Infância, experiência e linguagem em Walter Benjamin: a indústria cultural e as implicações pedagógicas do empobrecimento da experiência formativa. São Carlos: UFSCar, 2012. $125 \mathrm{f}$.

QUÉAU, Philippe. O tempo do virtual. In: PARENTE, André (org.). ImagemMáquina: a era das tecnologias do virtual. 3 ed. São Paulo: Ed. 34, 2001. p. 91-99.

TÜRCKE, C. Sociedade excitada: filosofia da sensação. Tradução Antonio A.S. Zuin, Fabio A. Durão, Francisco F. Fontanella, Mario Frungillo. Campinas, SP: Unicamp, 2010.

\section{Dados dos AUtOREs:}

Marsiel Pacífico

Doutor em Educação pela Universidade Federal de São Carlos. Professor Adjunto do Departamento de Métodos e Técnicas na Universidade Federal do Amazonas. Manaus/AM - Brasil. marsiellp@gmail.com

\section{Luiz Roberto Gomes}

Pós-doutor em ciências da educação pela J. W. Goethe Universität em Frankfurt am Main (Alemanha). Professor Associado do Departamento de Educação da Universidade Federal de São Carlos e Professor Permanente do Programa de Pós-graduação em Educação. São Carlos/SP - Brasil. luizroberto.gomes@gmail.com

Submetido em:28-7-2017

Aceito em: 7-12-2018 